\title{
Updating Traditional 1/50,000 Topographic Maps Using Crowd-Sourced Geodata and Free Sources Satellite Images
}

\author{
Atef Belhaj Ali, Mohamed Hafedh Hamza \\ Department of Geography and GIS, Faculty of Arts and Humanities, King Abdulaziz University, Jeddah, KSA \\ Email: amalhabeb@kau.edu.sa
}

How to cite this paper: Belhaj Ali, A. and Hamza, M.H. (2021) Updating Traditional 1/50,000 Topographic Maps Using CrowdSourced Geodata and Free Sources Satellite Images. Journal of Geographic Information System, 13, 274-286. https://doi.org/10.4236/jgis.2021.132015

Received: March 13, 2021

Accepted: April 24, 2021

Published: April 27, 2021

Copyright $\odot 2021$ by author(s) and Scientific Research Publishing Inc. This work is licensed under the Creative Commons Attribution International License (CC BY 4.0).

http://creativecommons.org/licenses/by/4.0/

\section{(c) (i) Open Access}

\begin{abstract}
This paper addresses how open geodata and crowd-sourced geodata, and the open geoportals might be integrated with the mainstream surveying and mapping practices to update traditional topomaps quickly and inexpensively, that might be otherwise impossible to do it due to economic and logistic situations. The abundant geographic data on the internet could be used to update topographic maps while avoiding the time-consuming nature of the traditional method. To be able to use them, it is necessary to measure and quantify the quality of these data, as well as to verify their credibility, in order to incorporate them into official topographic maps. The proposed approach takes advantage of neocartography, and it's not about further developing a new approaches, but looking differently at how data is collected, assembled controlled and been used for updating topomaps. At the beginning, the methodology used about how open geodata and crowd-sourced geodata involved in collecting, simplifying, generalizing, controlling and generating useful cartographic information that complement traditional and conventional counterparts is presented. This methodology was applied on a 1/50,000 topomap located in the north of Jeddah city (western region of Saudi Arabia), and we have demonstrated that by using this type of data, it is possible to update topographic maps quickly and at a lower cost while maintaining cartographic precision and accuracy standards.
\end{abstract}

\section{Keywords}

Topomaps, Map Update, Open Geodata, Crowed Sourced Geodata, Open Street Map (OSM), Geodata Quality, Hausdorff Distance

\section{Introduction}

Conventional methods of producing topographic maps have proven to be insuf- 
ficient to meet demand and need for cartographic materials, as they are slow and expensive. It can sometimes take a few years after the decision to issue a map on the date it is made available to users. All topographic maps are currently still produced using photogrammetric procedures, with the increasing use of computers and digital data. The different stages of charting require a combination of science, technology and art.

The first step which consists in taking aerial photographs from an airplane requires care, meticulous preparation as well as significant financial means. The shooting conditions for having exploitable photographs are very strict.

The following steps (restitution, completion work, writing and printing) sometimes take a long time, which means that the time taken to draw up the maps is very long. It is therefore likely that details of the cartographic landscape have already changed when the map was published. An update of the map is necessary after a certain number of years (it depends on the updating policy implemented by the national mapping agencies), because human constructions develop or change, and the details of the vegetation can be modified (disappearance of agricultural exploitation, forest, etc.).

Judging by the usefulness of topographic maps, one could say that they still have a great future ahead of them. However, with constantly evolving techniques, their forms and the procedures for their establishment are and will be further modified.

The techniques of land surveys in conjunction with the use of GPS are very precise, but this methodology is expensive and presents problems for the mapping of large and isolated regions. In the meantime, the city has undergone several changes, notably at the level of the road infrastructure and the structure of the land use, without an update of the basic cartography. Figure 1 illustrates the changes which took place during of the last two decades in a district located in the north of Jeddah city.

Nowadays, it is obvious that there is an abundance of geographic data at various levels of precision and resolution, as well as the ease with which it can be obtained: either data made available to users by established data producers, or VGI (Volunteered Geospatial Information) data constructed by users of geographic information themselves [1]. Indeed, this study demonstrates, through the analysis of existing data, the feasibility of updating topographic maps at a scale of 1:150,000 while adhering to cartographic standards, particularly in terms of information accuracy. Citizens have a lot of potential as a source of geographic
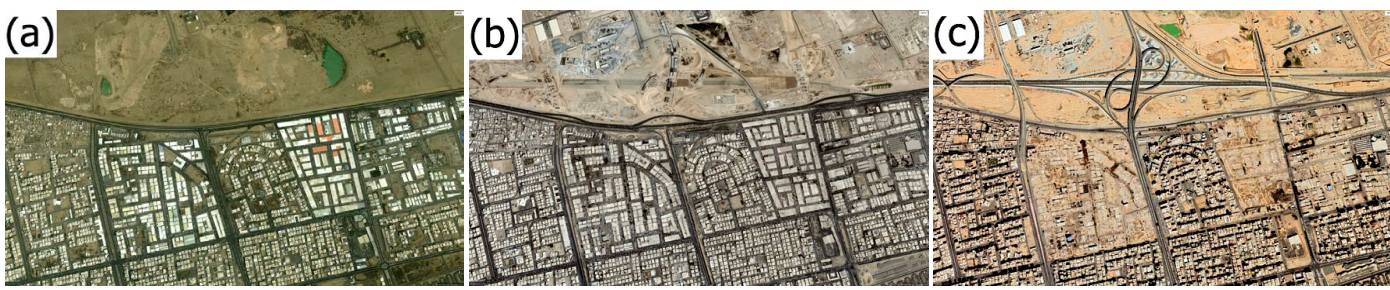

Figure 1. Changes occurred during a couple of decades (district located in the south of Jeddah airport) (a) 02/09/2001 (b) 05/05/2013 (c) $14 / 02 / 2020$. 
data, and the US National Academies have established this as strategic goal [2]. This study demonstrates through the analysis of existing data the possibility of updating topographic maps at a scale of 1:150,000 while respecting the cartographic standards, particularly with regard to the accuracy of the information. Citizen sensing has had a significant effect on mapping and map use, with implications for everyday activities. Google Earth, Bing Maps, and even citizen-generated maps created by projects like Open Street Map (OSM) are now commonly and regularly used by a wide range of amateur and technical communities. Furthermore, potentially radical impacts on mapping activity are likely [3] and some argue that VGI is attempting to bring in a new data-rich paradigm [4].

\section{Data and Methodology}

\subsection{Methodology}

This section introduces the available geodata used and also the proposed methodology for data quality analysis and date reliability before using them for updating north of Jeddah topo map at 1/50,000 scale (number 3921-43) as shown in Figure 2.

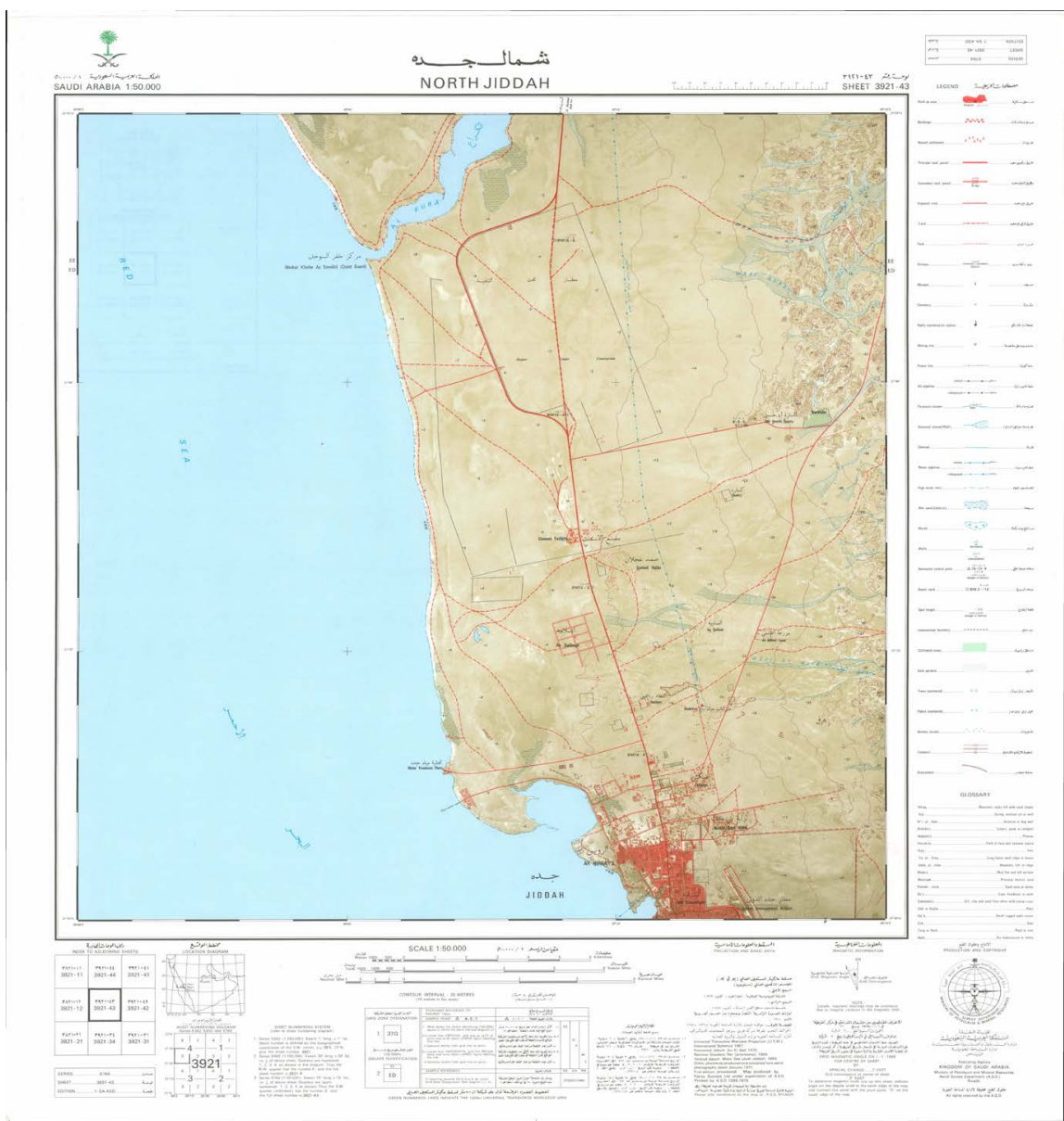

Figure 2. Old map of north of Jeddah at 1/50,000 scale (made from aerial photographs acquired in 1971 and printed in 1975). 
Since 2004, it has become obvious that users have the possibility to create their own geographic and cartographic data online in the form of maps, geographic databases or simply high-quality data layers, based on free data. Cartography knowledge, which was previously needed and classified as a highly restricted field, is no longer required, following the availability of free software and the production procedures that go with it. In addition, voluntary users could create local maps on areas in which they live, based on their local knowledge by implementing more or less effective products than a mapping expert who operates in a government agency.

Crowd-sourced geodata will be considered as the primary source of data. Indeed, Goodchild and Li [5] give three meanings to the term crowd-sourcing, the first finds its explanation in the terms crowd and outsourcing and calls for the resolution of a problem by a certain number of people without worrying of their technical qualifications. The other two definitions are more important in terms of quality assurance since they refer to a group's ability to correct errors made by others. Indeed the second meaning is based on the number of independent but consistent observations made by users. The third interpretation refers to the ability of the crowd to converge on the truth.

This section introduces the proposed methodology for updating the topographic map of north of Jeddah. Figure 3 illustrates the proposed methodology.

The methodology adopted is made up of the following steps:

1) Collection of data covering the study area (map to update). This step consists in looking for reliable and credible sources of crowd-sourced data that can be used for updating topographic maps. The sources used in this study are described in paragraph 2.2 .

2) Data preparation: this step consists in preparing the data inputs by georeferencing them in the same geographic/cartographic reference system. Landsat satellite images were orthorectified using the SRTM digital terrain model and ground control points gathered from the available maps.

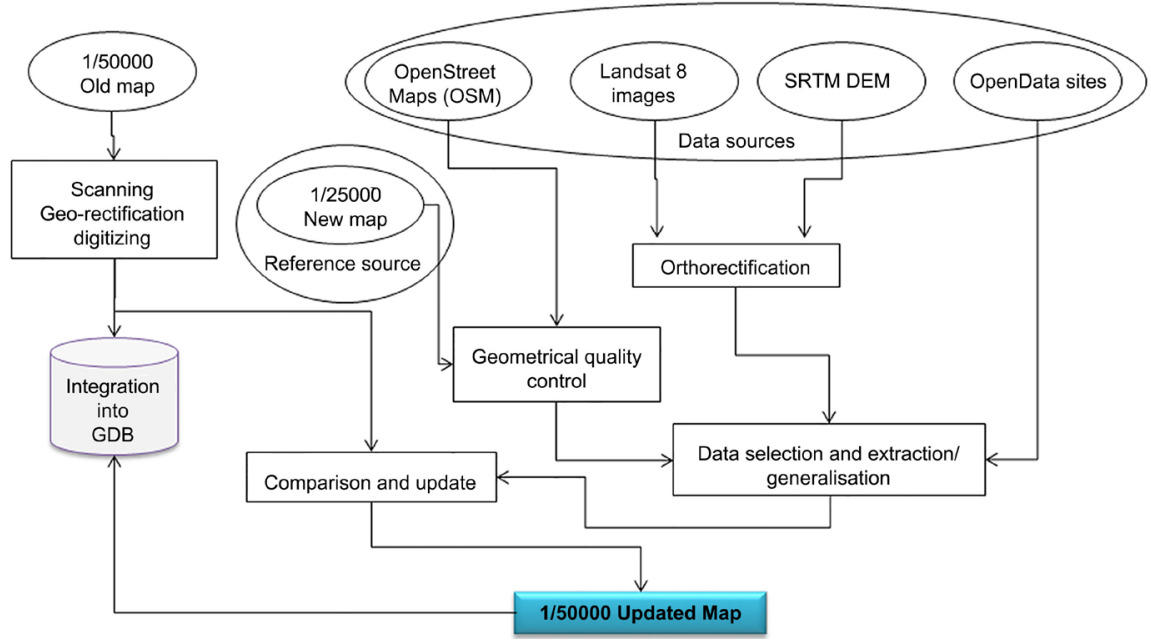

Figure 3. Proposed methodology. 
3) Quality control: during this step, all the data collected will be subjected to quality measurement operations. During this study, special interest is given on the geometric quality of vector data and mainly OSM data. This focus on OSM data is justified by the fact that these data will be used as a reference to calibrate all the other data.

4) Cartographic writing and final editing of the updated map.

\subsection{Main Used Data Sources}

In this section, the main sources of geodata used for updating the topographic map are presented.

\subsubsection{Google Earth/Google Maps Free Source Images/Data}

The google earth and google maps geoportals were two important sources for collecting the data needed for the map update. Indeed, the images provided by google earth were used through their photointerpretation to refine the land use layer. Google map data are used mainly at the level of toponymy and the POIs collection.

\subsubsection{Open Street Maps data}

Open street maps (OSM) was considered as a main reliable source for updating the topographic map. The choice of this source could be justified by the fact of the availability of this data as well as the sustained rate of its update. This kind of data can be extracted from The first is to identify a specific region and download the XML information found on the Open street map website

(https://www.openstreetmap.org/export\#map=11/21.5808/39.1656), the second is to use websites such as geofabrik (https://download.geofabrik.de/) or BBBike (https://extract.bbbike.org/). Figure 4 illustrates the downloaded OSM data that will be used in this study.

\subsubsection{Landsat Free Source Images}

The Landsat images acquired by the Landsat 8 OLI satellite Figure 5 provided free of charge through the site (earthexplorer.usgs.gov) were used to detect green areas whether inside the city or outside at the level of agricultural exploitations. the vegetation index were calculated Figure 5 and the layer representing this index was used as an aid during the photointerpretation of the establishment of the land cover layer.

\subsubsection{Other Crowd-Sourced and Open Geodata}

Other data sources, such as toponymy and POI data, were used. In reality, sites like Google Maps and Google Earth that provide daily updates were used. Official geoportals were also used, which provided free access to their data in order to verify the collected crowd sourced data or to gather geodata that was not available as crowd-sourced data.

For the altimetric data, the SRTM digital terrain models were used. The accuracy and reliability of this kind of data have been proven by several studies including that of Dawod [6], which showed through a reliability index based on 


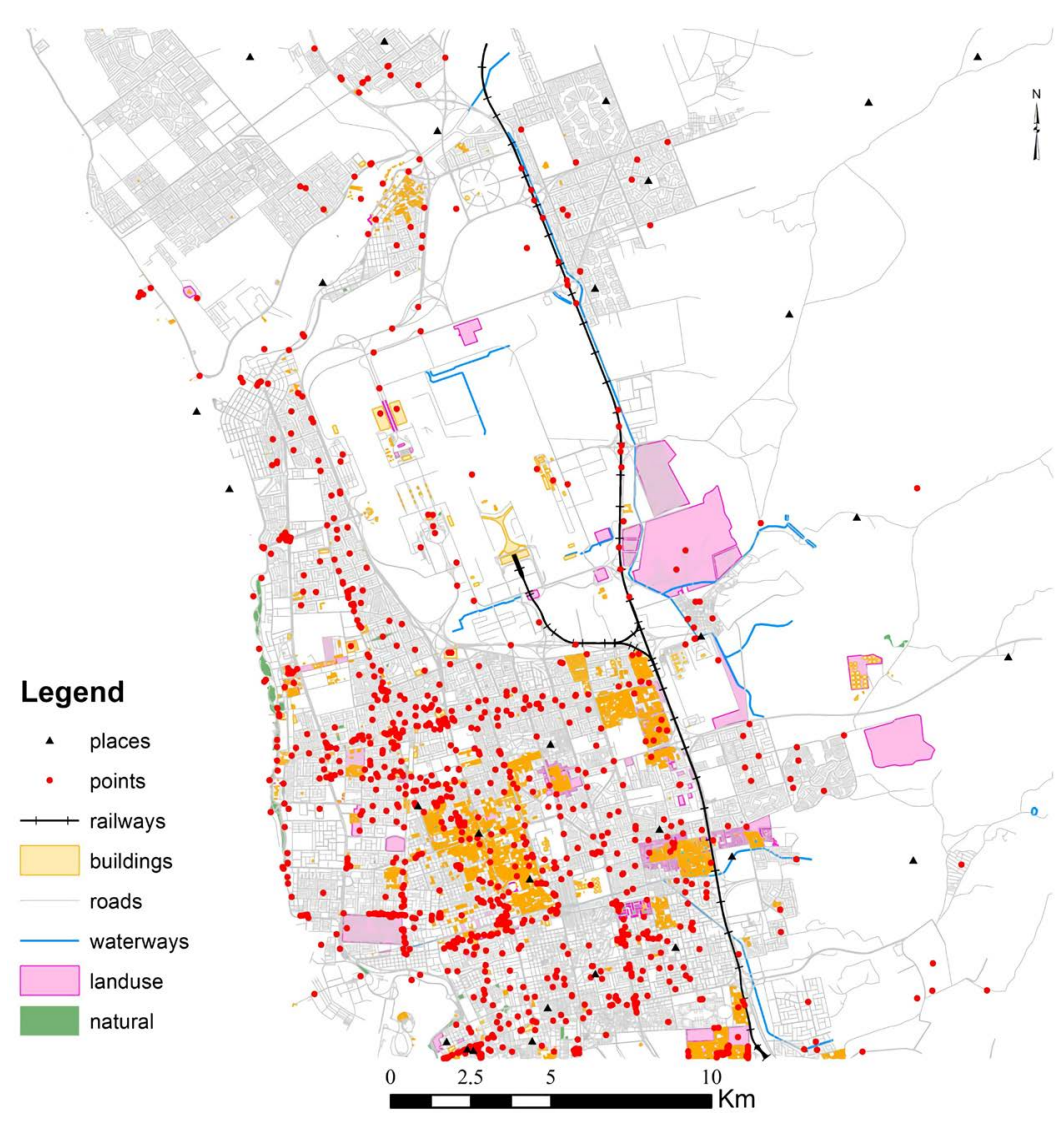

Figure 4. OSM vector data.
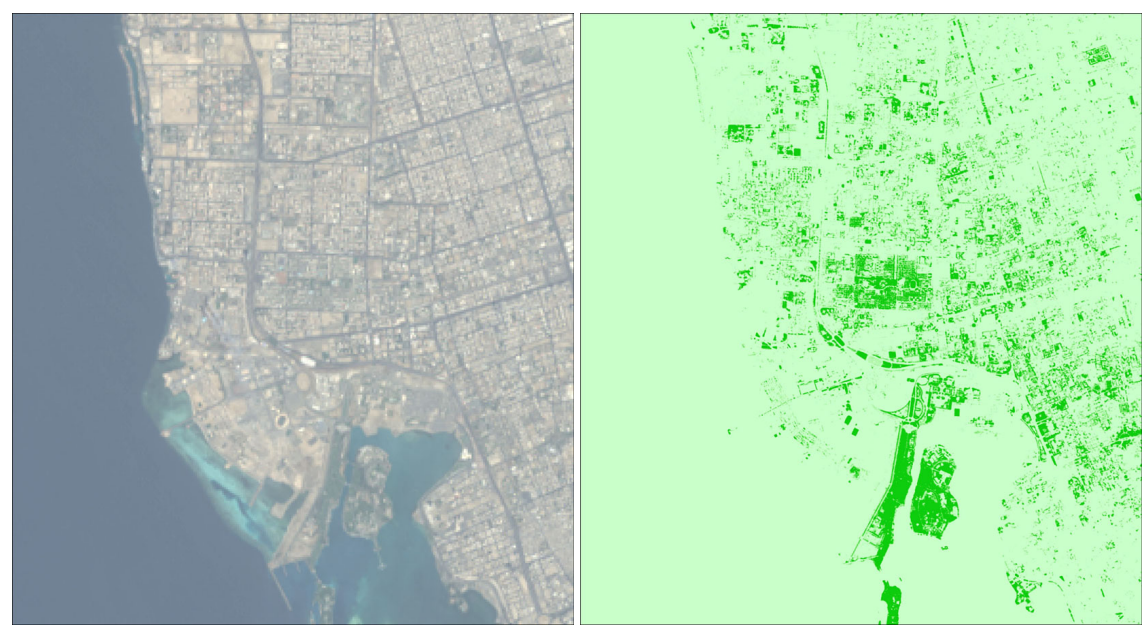

Figure 5. Image landsat 8 OLI and normalized difference vegetation index (NDVI index).

the weighted average concept and has been applied in two study areas in both Egypt and Saudi Arabia, that SRTM models attain high reliability indexes.

\section{Case Study: Update of North Jeddah Topographic Map}

\subsection{Quality Control}

Several studies have assessed the precision and accuracy of VGI and open data 
by comparing it with reference data. Mordechai Haklay [7] writes one of OSM's first quality reviews. This study focuses on the city of London and England. He found an average displacement of 6 meters by comparing OSM data with data from the Ordnance Survey of Great Britain. Furthermore, he noted substantial geographic variation in both geometric precision and completeness. He followed the simplest version of increasing buffer method [8] [9] to compare the linear objects, using a predefined buffer value (called $\varepsilon$ band) to calculate the corresponding overlap percentage. The set of inclusion rate measures constitutes an indicator, which takes the form of a function of the inclusion rate as a function of the value of $\varepsilon$. The authors have shown, by empirical tests, the plausibility of this indicator with a Gaussian model. This proof consists in determining the value $\varepsilon$ for a given probability $\mathrm{p}$ (the inclusion percentage) by admitting that $\mathrm{p}$ follows a Gaussian distribution. Bel hadj ali [10] states that the demonstration made by the authors is empirical and was conducted on an example and that it is difficult to confirm that it follows a Gaussian distribution on other dataset.

Girres and Toya [11] and Cipeluch et al. [12] also conducted studies, respectively, on France and Ireland, comparing OSM data to other sources such as google maps and bing maps, while emphasizing product accuracy without identifying mechanisms that can help ensure and improve quality.

To measure the geometric deviations of the OSM data, in particular the streets layer, the Hausdorff distance were used (Figure 6), by comparing the OSM data (after selection and generalization) with the data extracted from the topographic map at $1 / 25,000$ scale (map update in 2014). As hypothesis, the $1 / 25,000$ map is considered as the nominal terrain and de facto the reference for the measurements of the geometric deviations.

The Hausdorff distance is a classic and already defined by Hausdorff in 1937 [13], this distance has been taken up by researchers to use it as a metric to measure the geometric deviations between the linear and surface primitives [10] [14]. The Hausdorff distance is stated as follows:

Let $X$ and $Y$ are two non-empty subsets (primitives) of a metric space $(M, d)$. The Hausdorff distance $d_{H}(X, Y)$ between $X$ and $Y$ is defined by:

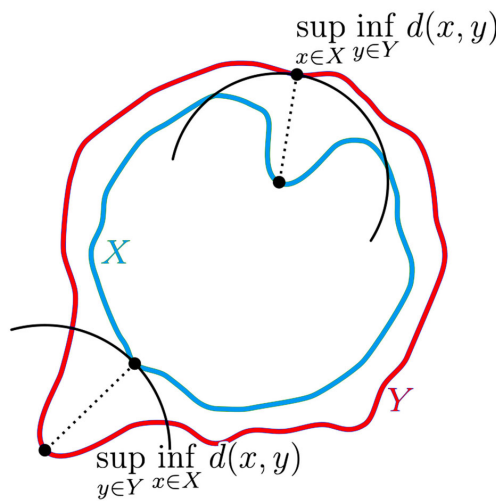

Figure 6. Hausdorff distance (figure borrowed from https://en.wikipedia.org/wiki/Hausdorff_distance). 


$$
d_{H}(X, Y)=\max \left\{\operatorname{SUP}_{x \in X} \underset{y \in Y}{\operatorname{INF}} d(x, y), \mathrm{SUP}_{y \in Y} \underset{x \in X}{\operatorname{INF}} d(x, y)\right\}
$$

where SUP represents Suprenum and INF the infimum

The displacement measurements based on the use of the Hausdorff distance have been conducted on roads and over an entire 1/25,000 map extent. The geometrical quality is assessed using road layer, because this data will be used as a main data on which will be positioned all the other layers and will also be used for the generation of other secondary data such as land use. Indeed, the variations between roads from the OSM dataset and those digitized from a topographic map at 1/25,000 (the nominal terrain) were calculated. The sample subjected to the measurements is composed of 4 categories (primary, secondary, tertiary and residential lanes) as shown in Figure 7. All the roads have been matched with those from the 1/25,000 map before measuring Hausdorff distance.

The accuracy of the map means the error value between the measurements (dimensions and areas) on the map and between the actual dimensions of the same features in nature (nominal terrain). The accuracy of the printed map is determined according to its scale, whereby the authorities in each country determine the required specifications of the measurements to prepare their maps, and we mention, for example, the United States Geological Survey (http://www.usgs.gov), where the horizontal accuracy of its maps was determined at a scale of 1/63,000 by 32.18 meters. The Egyptian General Survey Authority (http://www.esa.gov.eg) also determined the horizontal resolution of maps at a scale of $1 / 50,000$ by 25 meters.

As mentioned previously, the displacements between the OSM data and the data digitized from the 1/25,000 map will be measured by the Hausdorff distance. Table 1 below illustrates the measurements.

The following Figure 8 illustrates the histograms of the Hausdorff distance measurements.
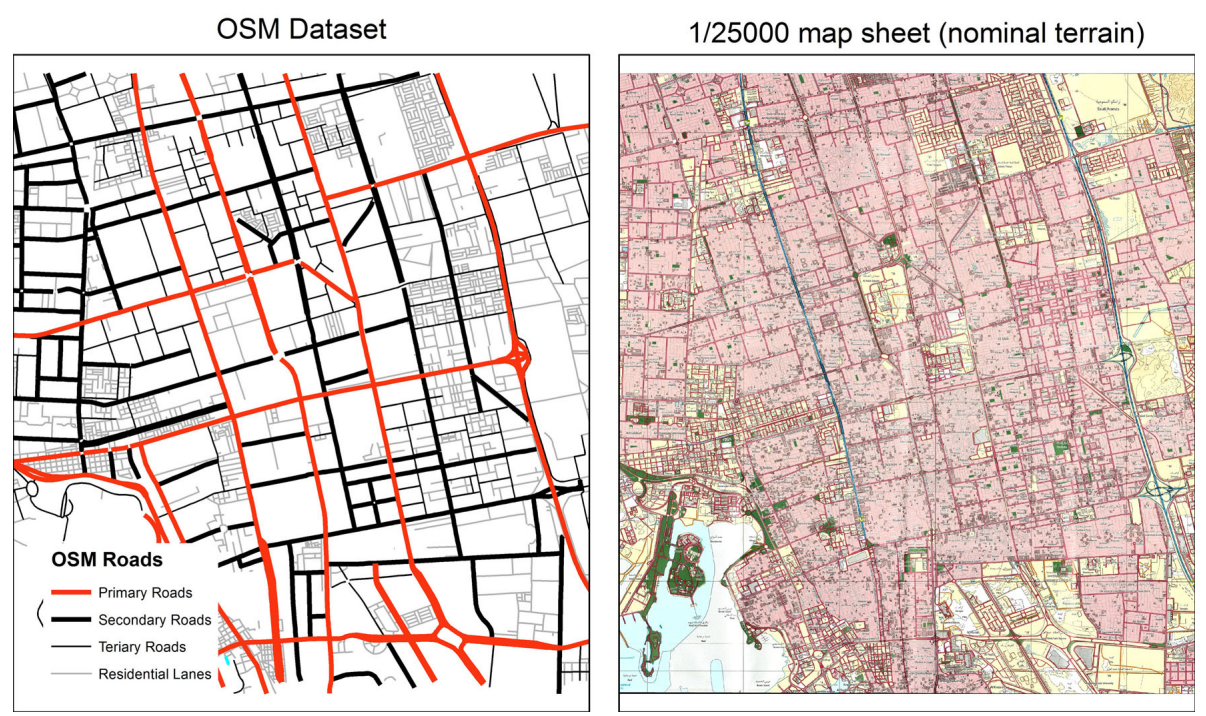

Figure 7. OSM dataset (after selection et generalisation) used to assess geometrical quality. 
Table 1. Hausdorff distance measurements.

\begin{tabular}{cccccc}
\hline \multirow{2}{*}{ Road type } & \multirow{2}{*}{$\begin{array}{c}\text { Sample size } \\
\text { (road/section of road) }\end{array}$} & Min & Max & Average & $9^{\text {th }}$ percentile \\
\cline { 3 - 6 } & 99 & 0.481 & 36.542 & 11.911 & 24.112 \\
Primary & 161 & 1.424 & 21.085 & 8.629 & 15.885 \\
secondary & 254 & 0.566 & 24.672 & 8.497 & 15.28 \\
Tertiary & 2444 & 0.152 & 27.4 & 6.48 & 13.237 \\
Residential lanes & & &
\end{tabular}

Histograms (Hausdorff Distance) Primary Roads

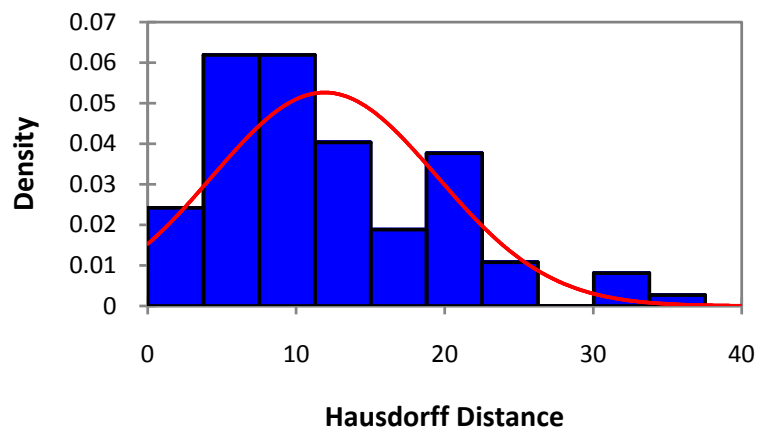

$$
\begin{aligned}
& \text { Hausdorff Distance } \\
& \text { Normal Distribution }(11.911 ; 7.577)
\end{aligned}
$$

Histograms (Hausdorff Distance) Tertiary Roads
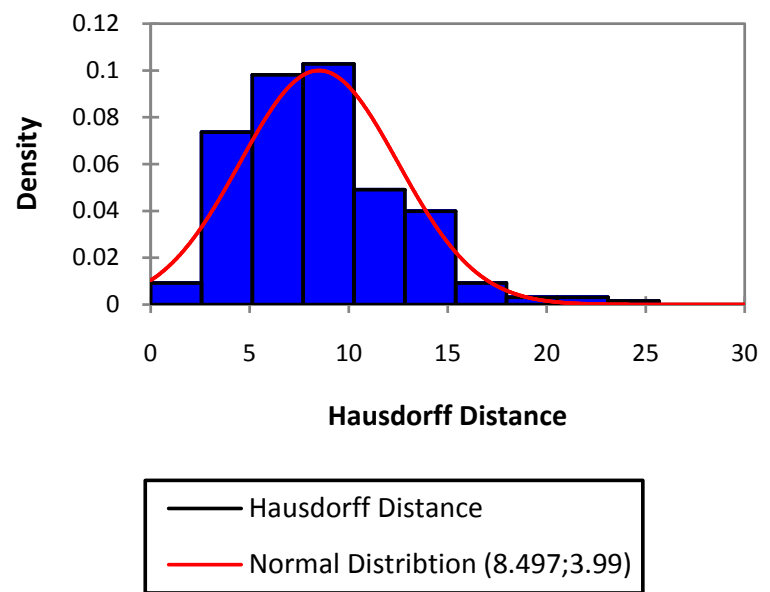

\section{Histograms (Hausdorff Distance)} Secondary Roads
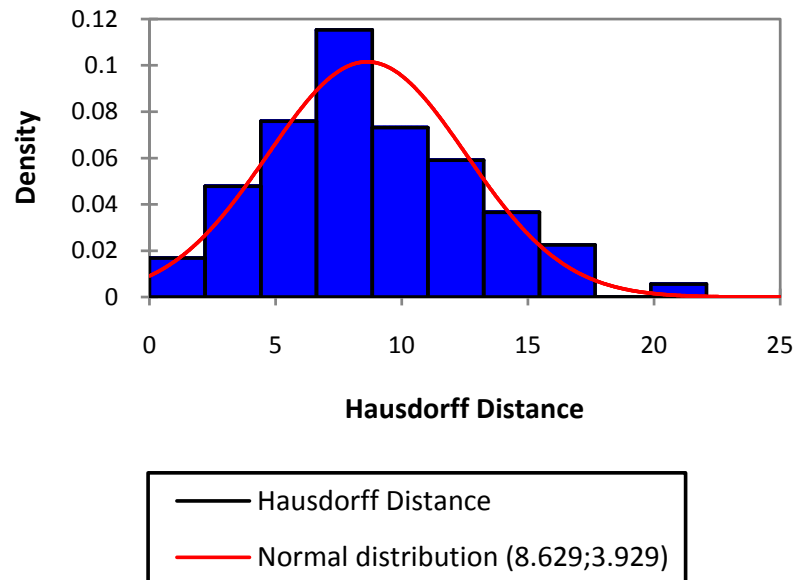

Histograms (Hausdorff Distance) Residential Lanes
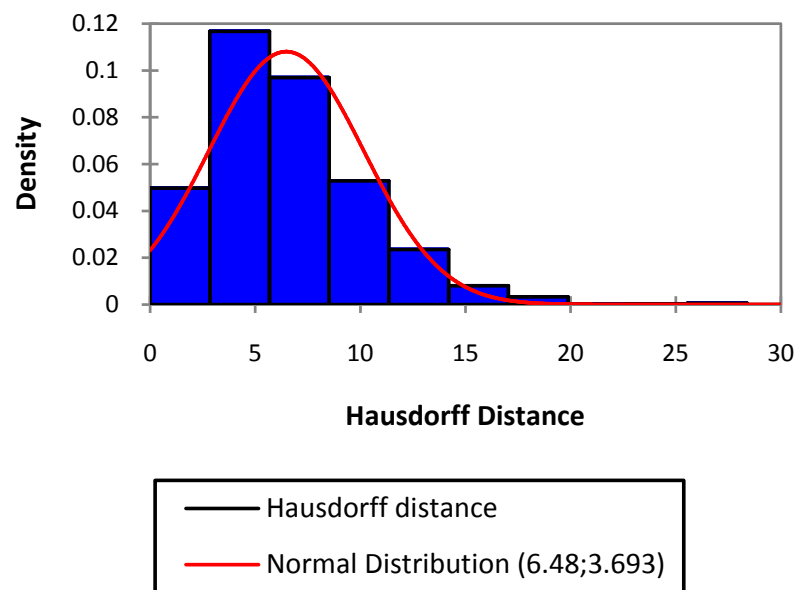

Figure 8. Histograms of the Hausdorff distance measurements.

The test of normality was carried out in order to verify if the measurements of the Hausdorff distance follow a normal law, the results show that the deviations in no way follow the normal law. It would be interesting to continue the investigations and seek the probabilistic law which governs these deviations. Further- 
more, the deviation measurements obtained (Table 1) remain within the standards as defined by the national and international authorities in charge of mapping. In addition, the measurements of deviations obtained remain within the standards as defined by the national and international authorities in charge of mapping. Therefore, the OSM layer of roads meets the requirements of geometric precision for a map at the scale of 1:50,000, therefore it was used as a reference layer on which will be positioned all the other information necessary to. Update the topographic map and generate other information based on this layer.

Regarding semantic precision [7] assessed the amount of attributes over the whole of England. He noticed that the latter was very weak and progressed much more slowly than the geometry. Indeed, geometric coverage has improved over the years while the progression of attribute information has not kept pace [14]. The main reason is that it is necessary to use other sources of information and to cross-reference them.

\subsection{Data Gathering and Production}

Table 2 shows all the main sources used in this study.

The following figure (Figure 9) illustrates two samples of 1/50,000 topomap. The first sample shows the old topographic map and the other one illustrates the result of our study showing the map after its update by using the crowd-sourced and open geodata.

Table 2. Main geodata sources.

\begin{tabular}{|c|c|c|}
\hline Layer & Data source & Observations \\
\hline Contours and elevation points & srtm.csi.cgiar.org/srtmdata & The data was derived from SRTM DEM \\
\hline Bathymetry & http://www.gebco.net & $\begin{array}{l}\text { The data was derived for openseamap from the } \\
\text { GEBCO_2014 Grid }\end{array}$ \\
\hline Roads and Railroads & $\underline{\text { https://extract.bbbike.org/ }}$ & $\begin{array}{l}\text { Open street map (after selection, generalization } \\
\text { and simplification) }\end{array}$ \\
\hline Land use & $\begin{array}{l}\text { - Open Street map } \\
\text { - Google earth } \\
\text { - Landsat images }\end{array}$ & $\begin{array}{l}\text { The data was derived from OSM road layer and } \\
\text { completed and verified by interpreting Landsat } \\
\text { images and google earth images }\end{array}$ \\
\hline & - Google maps & \\
\hline Points of interest (POIs) & - Google earth & The data was gathered and verified from various \\
\hline Toponyms & $\begin{array}{l}\text { - Geoportal of Jeddah Municipality (smartmap.jeddah.gov.sa) } \\
\text { - Saudi addresses geoportal (maps.adress.gov.sa) }\end{array}$ & sources (crowd-sourced and official data) \\
\hline Industrial areas & https://modon.gov.sa/ar/Pages/default.aspx & $\begin{array}{l}\text { Free data provided by the Saudi authority for } \\
\text { industrial cities and technology zones }\end{array}$ \\
\hline hydrography & $\begin{array}{l}\text { - Old maps } \\
\text { - SRTM DEM } \\
\text { - Landsat images }\end{array}$ & $\begin{array}{l}\text { The data was digitized from legacy maps, and } \\
\text { updated by thalweg layer extracted from SRTM } \\
\text { DEM and verified by the photo interpretation of } \\
\text { Landsat image }\end{array}$ \\
\hline Green areas & Landsat images (downloaded from earthexplorer.usgs.gov) & $\begin{array}{l}\text { The data was extracted from Normalized } \\
\text { Difference Vegetation Index (NDVI) }\end{array}$ \\
\hline
\end{tabular}




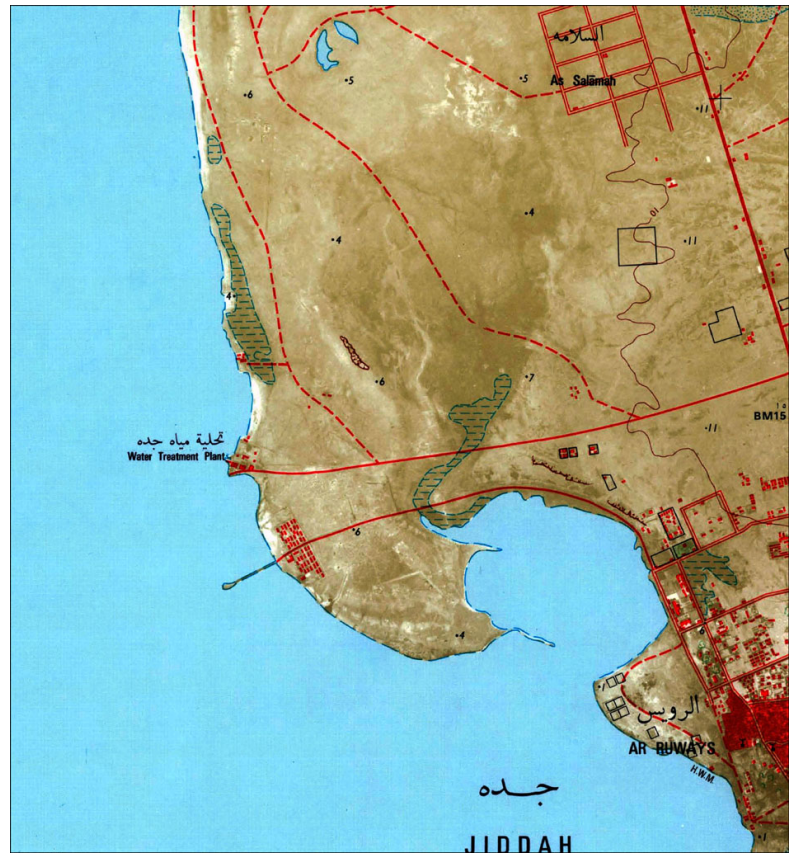

(a)

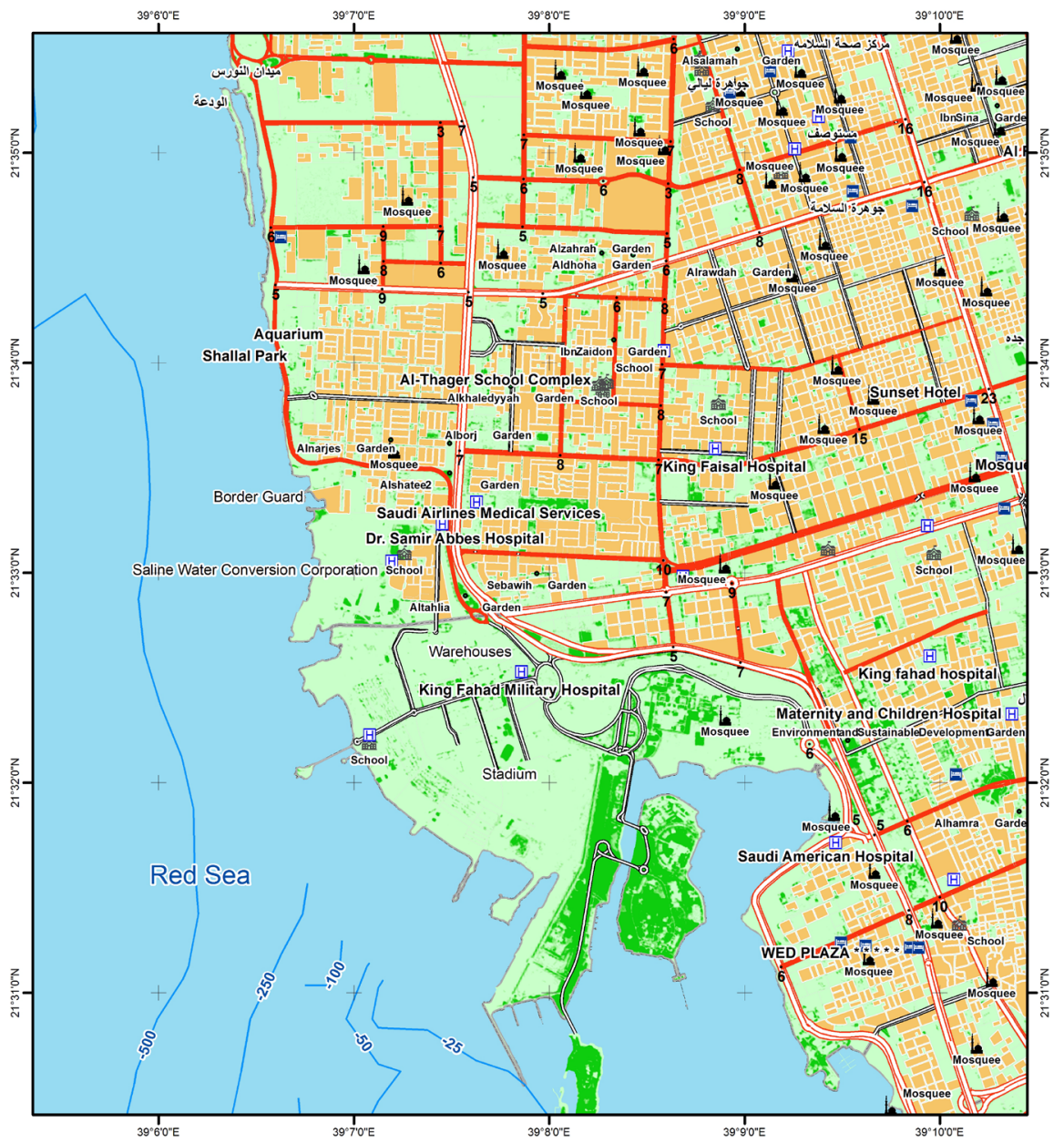

(b)

Figure 9. (a) Sample of the old map, (b) sample of the updated map. 


\section{Conclusions}

This paper demonstrates the value of using crowd-sourced and open geodata to update the basic topographic map at a scale of 1:50,000. The chosen study area is located north of Jeddah (KSA's Western region), an area that benefits from an abundance of free geographic data on the one hand, and data made available by national authorities on the other. The topographic map used as example for the update was created from aerial photographs acquired in 1971 and printed and made available to users in 1975.

In reality, this topographic map hasn't been updated in 50 years, so updating it will be the same as creating it from scratch. Within the scope of this paper, a search for the different sources of data likely to be used for the update was conducted. The reliability of the sources listed, as well as the consistency of the data they provide, has been evaluated. The OSM data was given special attention, especially the road network layer, which served as a guide for all the other layers. The 95th percentile deviations range from 13 meters (for residential lanes) to 24 meters (for the primary roads). While the geometry meets the specifications, the data's completeness is sometimes missing, forcing us to compile data from various sources.

Finally, it was demonstrated that there are significant benefits to using crowd-sourced and open geodata in map revision and update, especially for agencies and authorities that use a continuous rather than cyclical updating strategy. As a result, it is strongly advised that mapping agencies build channels that can accept citizen contributions and put in place processes to ensure the data's integrity and completeness.

\section{Acknowledgements}

This project was funded by the Deanship of Scientific Research (DSR) at King Abdulaziz University, Jeddah, under grant No. G-536-125-1434. The authors, therefore, acknowledge with thanks DSR for technical and financial support. Dr. Atef BELHAJ ALI, Principal Investigator.

\section{Conflicts of Interest}

The authors declare no conflicts of interest regarding the publication of this paper.

\section{References}

[1] Goodchild, M.F. (2007) Citizens as Sensors: The World of Volunteered Geography. GeoJournal, 69, 211-221. https://doi.org/10.1007/s10708-007-9111-y

[2] Committee on Strategic Directions for the Geographical Sciences in the Next Decade (CSDGSND) (2010) Understanding the Changing Planet: Strategic Directions for the Geographical Sciences. National Academies Press, Washington DC.

[3] Olteanu-Raimond, A.-M., Hart, G., Foody, G., Touya, G., Kellenberger, T. and Demetriou, D. (2017) The Scale of VGI in Map Production: A Perspective of European 
National Mapping Agencies. Transactions in GIS, 21, 74-90. https://doi.org/10.1111/tgis.12189

[4] Jiang, B. and Thill, J.-C. (2015) Volunteered Geographic Information: Towards the Establishment of a New Paradigm. Computers, Environment and Urban Systems, 53, 1-3. https://doi.org/10.1016/j.compenvurbsys.2015.09.011

[5] Goodchild, M.F. and Li, L. (2012) Assuring the Quality of Volunteered Geographic Information. Spatial Statistics, 1, 100-120. https://doi.org/10.1016/j.spasta.2012.03.002

[6] Dawod, G. and Al-Ghamdi, K. (2017) Reliability of Recent Global Digital Elevation Models for Geomatics Applications in Egypt and Saudi Arabia. Journal of Geographic Information System, 9, 685-698. https://doi.org/10.4236/jgis.2017.96043

[7] Haklay, M. (2010) How Good Is Volunteered Geographical Information? A Comparative Study of OpenStreetMap and Ordnance Survey Datasets. Environment and Planning B: Planning and Design, 37, 682-703. https://doi.org/10.1068/b35097

[8] Goodchild, M.F. and Hunter, G. (1997) A Simple Positional Accuracy Measure for Linear Features. International Journal of Geographical Information Systems, 11, 299-306. https://doi.org/10.1080/136588197242419

[9] Hunter, G.J., Goodchild, M.F. and Robey, M. (1994) A Toolbox for Assessing Uncertainty in Spatial Databases. The Proceeding of the Annual Conference of the Australasian Urban and Regional Information Systems Association, Sydney, 25-27 July 1994, 367-379.

[10] Ali, A.B. (2001) Qualité géométrique des entités géographiques surfaciques: Application à l'appariement et définition d'une typologie des écarts géométriques. Thèse de Doctorat, université de Marne La Vallée.

[11] Girres, J.F. and Touya, G. (2010) Quality Assessment of the French OpenStreetMap Dataset. Transactions in GIS, 14, 435-459. https://doi.org/10.1111/j.1467-9671.2010.01203.x

[12] Ciepluch, B., Jacob, R., Mooney, P. and Winstanley, A. (2010) Comparison of the Accuracy of OpenStreetMap for Ireland with GoogleMaps and Bing Maps. Proceedings of the 9th International Symposium on Spatial Accuracy Assessment in Natural Resources and Environmental Science, Leicester, 20-23 July 2010, 4 p.

[13] Hausdorff, F. (1957) Set Theory. Chelsea, New York. Traduction de la troisième édition de Mengenlehre, 1937.

[14] Abbas, I. (1994) Bases de données vectorielles et erreur cartographique. Problèmes posés par le contrôle ponctuel; une méthode alternative fondée sur la distance de Hausdorff. Thèse de doctorat, Université de Paris VII, Paris.

[15] Petit, O., Billon, P. and Follin, J.-M. (2012) Évaluation de la qualité des données OpenStreetMap sur la Sarthe et réflexion sur le processus de contribution. Revue $X Y Z, 131,37$. 